\title{
Aerosol Chamber Characterization for Commercial Particulate Matter (PM) Sensor Evaluation
}

\author{
Dian Ahmad Hapidin ${ }^{1,3}$, Casmika Saputra ${ }^{1,3}$, Dian Syah Maulana ${ }^{1,3}$, \\ Muhammad Miftahul Munir ${ }^{1,2,3^{*}}$, Khairurrijal Khairurrijal ${ }^{1,2,3^{* *}}$ \\ ${ }^{1}$ Department of Physics, Faculty of Mathematics and Natural Sciences, Institut Teknologi Bandung, Bandung 40132, \\ Indonesia \\ ${ }^{2}$ Research Center for Biosciences and Biotechnology, Institute for Research and Community Services, Institut Teknologi \\ Bandung, Bandung 40132, Indonesia \\ ${ }^{3}$ Research Center for Disasters Mitigation, Institute for Research and Community Services, Institut Teknologi Bandung, \\ Bandung 40132, Indonesia
}

\begin{abstract}
The negative impact of $\mathrm{PM}_{2.5}$ exposure has encouraged the development of scattering-based PM sensors for monitoring the PM level spatially and temporally. These PM sensors excel in terms of cost, operating power, and compactness, but the performance of each model needs to be evaluated individually. The evaluation of a PM sensor can be conducted inside an aerosol chamber by measuring the PM concentration in time series using both the sensor and reference monitors. However, earlier experimental processes were time-consuming, as a long time was needed to decrease the PM concentration by loss mechanisms. We designed an aerosol chamber by introducing an output airflow rate to decay the PM concentration more quickly. The characterization of the chamber yielded an empirical equation to describe the PM concentration decay profile, which can be used to predict the measurement time and the number of data points. The chamber was then utilized to evaluate three PM sensors (Sharp GP2Y1010AU0F, Winsen ZH03A, and Novafitness SDS011). A condensation particle counter (TSI, 3025A) and particle sensor (Honeywell, HPMA115S0-XXX) were employed as reference monitors. The evaluation determined the linearity, calibration curve, and precision of the PM sensors. The evaluated models showed excellent linearity, with $\mathrm{R}^{2}$ values above 0.956 . The least square and RMA correlation of the evaluated PM sensors demonstrated the best linearity achieved at a low PM measurement range $\left(0-400 \mu \mathrm{g} \mathrm{m}^{-3}\right)$. As the Winsen ZH03A and Novafitness SDS011 sensors had coefficients of variation below $10 \%$, both of the sensors have an acceptable precision according to the EPA standard.
\end{abstract}

Keywords: Aerosol chamber; Air pollution; Particulate matter; $\mathrm{PM}_{2.5}$ monitor; $\mathrm{PM}$ sensor.

\section{INTRODUCTION}

Particulate matter (PM) has been known as an essential key for determining air quality due to its negative impact to the respiratory system (Karlsson et al., 2009), climate (IPCC et al., 2013), and environment (Sahani et al., 2014). $\mathrm{PM}$ with aerodynamic diameter smaller than $2.5 \mu \mathrm{m}\left(\mathrm{PM}_{2.5}\right)$ and $10 \mu \mathrm{m}\left(\mathrm{PM}_{10}\right)$ can originate from various sources, such as vehicle emission (Yan et al., 2011), industrial emission

\footnotetext{
* Corresponding author.

Tel.: +62-22-250-0834

E-mail address: miftah@fi.itb.ac.id

** Corresponding author.

Tel.: +62-22-250-0834

E-mail address: krijal@fi.itb.ac.id
}

(Abril et al., 2016), and biomass burning (Betha et al., 2013; Sahani et al., 2014; Fujii et al., 2015). $\mathrm{PM}_{2.5}$ and $\mathrm{PM}_{10}$ can easily enter the respiratory system and $\mathrm{PM}_{2.5}$ can even get into lungs alveoli and cause damage (Lestari and Savitri, 2003; Fujii et al., 2015). Accordingly, WHO recommends $\mathrm{PM}_{2.5}$ concentration for short-term ( 24 hours) and long-term (1 year) exposure below $25 \mu \mathrm{g} \mathrm{m} \mathrm{m}^{-3}$ and $10 \mu \mathrm{g} \mathrm{m} \mathrm{m}^{-3}$, respectively (WHO, 2005). In some developing countries, e.g., China, India, Bangladesh, and Pakistan, $\mathrm{PM}_{2.5}$ pollution has been a severe problem because its concentration exceeds the recommended level that leads to a high number of mortalities (Cheng et al., 2013; Shi et al., 2018). Therefore, spatial and temporal monitoring of PM concentration is needed to determine regulations and actions regarding the $\mathrm{PM}_{2.5}$ source.

PM concentration can be measured by various instruments, such as optical particle counter (OPC) (Chien et al., 2016), condensation particle counter (CPC) (Hermann et al., 
2007), and tapered element oscillating microbalance (TEOM) (Patashnick and Rupprecht, 1991). Although these instruments have excellent measurement performances, they are cost inefficient for a large-scale distributed PM monitoring system. A new trend has been emerging to use light scattering-based PM sensors for annual spatial and temporal $\mathrm{PM}_{2.5}$ monitoring system because of their compactness, low power, and low cost (Jovašević-Stojanović et al., 2015; Rai et al., 2017; Soysal et al., 2017; Li et al., 2018). However, these sensors have different responses for different types of particles so that performance evaluation procedures need to be made (Dacunto et al., 2015; Li and Biswas, 2017).

The performance evaluation of PM sensors are usually done inside an aerosol chamber in which physical parameters can be maintained (Wang et al., 2015; Manikonda et al., 2016; Li and Biswas, 2017). Many researchers evaluated PM sensors by comparing their outputs to reference monitors while the PM concentration inside the chamber was decayed by concentration loss mechanisms such as wall deposition and gravitational precipitation (Dacunto et al., 2015; Wang et al., 2015; Manikonda et al., 2016; Li and Biswas, 2017; Li et al., 2018). These methods are useful when aerosol sources are difficult to control, such as cigarette smoke (Manikonda et al., 2016), incense smoke (Wang et al., 2015; Li et al., 2018), and welding fume (Sousan et al., 2017). On the other hand, their data logging processes are time-consuming as they need hours to decay the PM concentration near to zero by the concentration loss mechanisms (Wang et al., 2015; Manikonda et al., 2016). Furthermore, these concentration loss mechanisms are a size-dependent process, which will likely shift the particle size distribution over time if particles with wide size distribution are used in the experiment (Bowman et al., 1997; Cocker et al., 2001; Wang et al., 2014; Zhao et al., 2015). If the experiment is performed in a relatively long time, the particle size distribution may not represent its original properties.

To overcome these limitations, we designed an aerosol chamber with the introduction of an output airflow rate $\left(Q_{\text {out }}\right)$ to decay the PM concentration. Consequently, the experiment time, as well as the number of measurement data points, reduced significantly. To optimize both the experiment time and the number of measurement data points, we studied the characteristics of PM concentration decay inside the aerosol chamber. We also examined the utilization of the aerosol chamber for laboratory evaluation of three commercial PM sensors, i.e., Sharp GP2Y1010AU0F, Winsen ZH03A, and Novafitness SDS011. The reference monitors for the evaluation employed a CPC (TSI, 3025A) and a factory-fully calibrated particle sensor (Honeywell, HPMA115S0-XXX). $\mathrm{PM}_{2.5}$ from incense burning smoke was used as a particles source for the aerosol chamber characterization and PM sensors evaluation. The laboratory evaluation of the commercial PM sensors yielded the following characteristics: sensor linearity, calibration curve, and precision. These characteristics are important to guarantee the reliability of the PM sensors for applications in industry, health, and environment as either pollution detectors or monitoring devices.

This paper will be presented in two sections; the first section will talk about the characterization of the aerosol chamber and the second section will point out the evaluation of the PM sensors in the aerosol chamber. The study on concentration decay inside the aerosol chamber will predict the experiment time and the number of data points that will later be used to evaluate the PM sensors. The experimental methods to characterize the aerosol chamber and evaluate the PM sensors will be discussed in detail.

\section{METHODS}

\section{Aerosol Chamber and Experimental Setup}

Fig. 1 shows the experimental setup of aerosol chamber, $\mathrm{PM}_{2.5}$ generator, airflow system and measurement instruments (PM sensors and reference monitors). The aerosol chamber was custom built with a transparent acrylic sheet and had a good impermeability to maintain measurement condition and eliminate environmental disturbance. Each side of the chamber (except for the door) was permanently glued to prevent air leakage. On the right side of the chamber, the sealed fittings were installed for air pipe and electrical cable.

A CPC (TSI, 3025A) and a factory-calibrated particle sensor (Honeywell, HPMA115S0-XXX), abbreviated as HPMA, were applied as reference monitors. The reference monitors were placed adjacent to the evaluated PM sensors (Sharp, GP2Y1010AU0F, abbreviated as GP2Y; Winsen, ZH03A, as ZH03; and Novafitness, SDS011, as SDS0) to minimize the spatial difference of PM concentration.

The PM source for the experiment was from burning incense sticks. Many aerosol experiments have used the incense smoke due to its excellent representation of a $\mathrm{PM}_{2.5}$ source (Dacunto et al., 2015; Liu et al., 2015; Wang et al., 2015; Zhang et al., 2016). The incense smoke particle distribution was measured by an optical particle counter (OPC) (Rion, KC-03), which only provides five bins for sizing the particles. To refine the particle size distribution, we applied a pulse-height analysis method to the output voltage of the OPC (Gu et al., 2010). Note that the OPC measures the number of particles by counting the number of voltage pulses from its photodetector. Moreover, as the voltage pulse is caused by the light scattering of single particle, the pulse height will be proportional to the particle size (Heim et al., 2008). Based on this measurement principle, a pulse-height analyzer (PHA) was custom made, which has a high-speed analog to digital converter (Contec, AIO160802AY) connected to the OPC output port to record and process the voltage pulse data. Custom-made software then counted the voltage pulses and analyzed their height. The custom-made PHA was calibrated by employing polystyrene latex spherical particles with geometric mean diameters of 160, 308, 451, and $565 \mathrm{~nm}$. Fig. 2 shows the particle size distribution of the incense smoke with three measurement runs. The particle size distribution had a single peak (mode size at approximately $330 \mathrm{~nm}$ ) with most of the particles were less than $1 \mu \mathrm{m}$ in size, which is in accordance with the measurement data reported by Wang et al. (2015). 


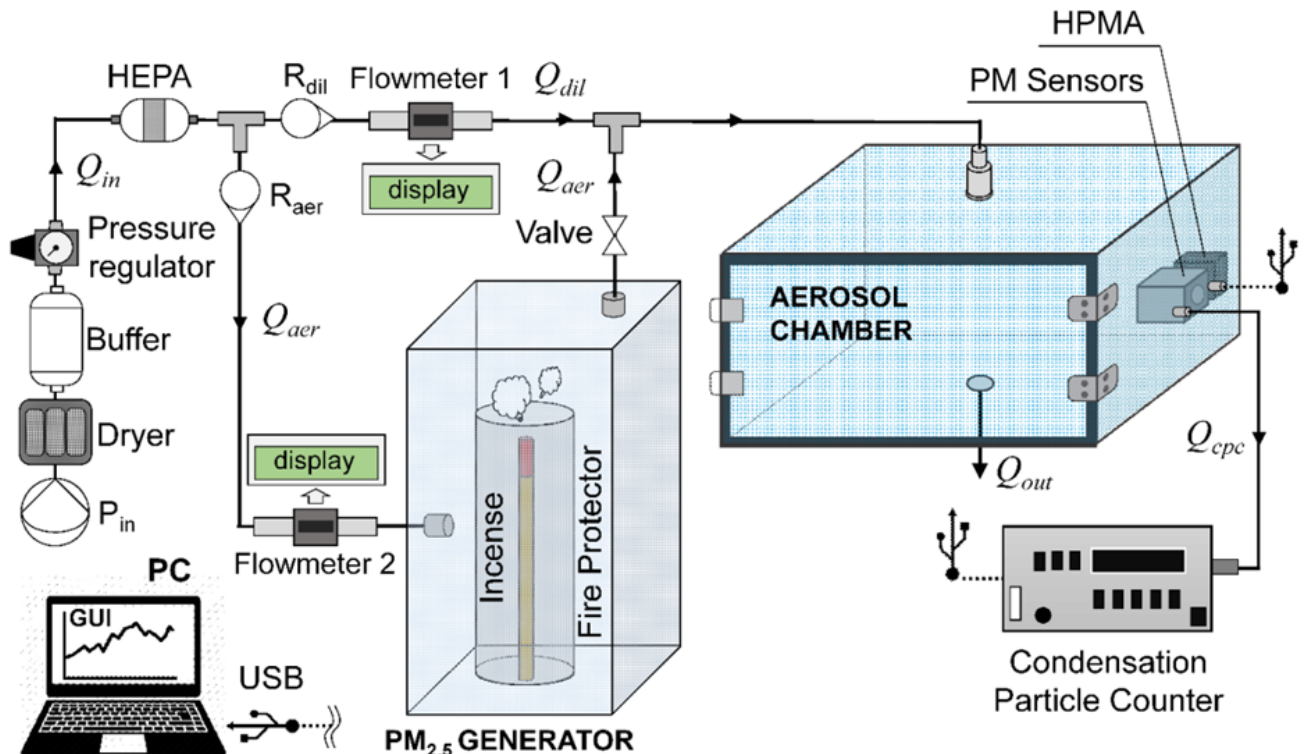

Fig. 1. Experimental setup to characterize the aerosol chamber and evaluate the PM sensors.

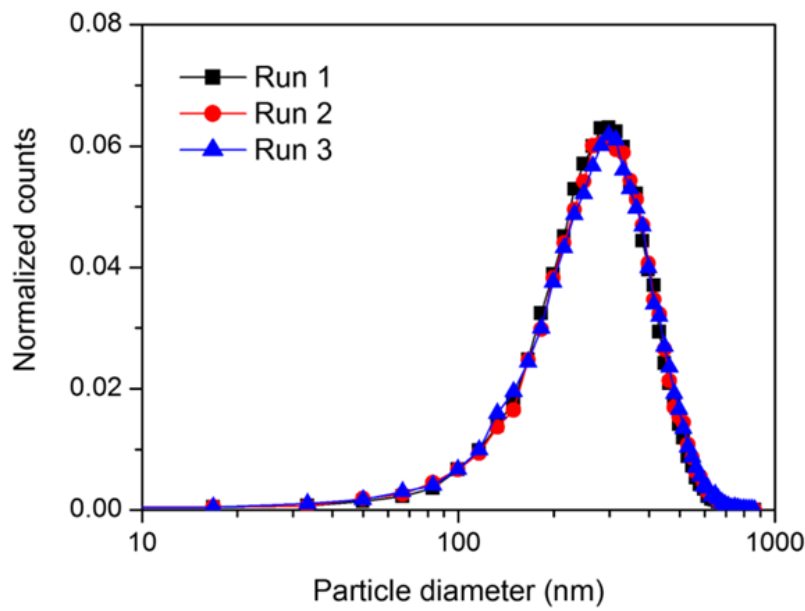

Fig. 2. The particle size distributions of incense smoke, which were measured by pulse-height analysis (PHA) to the output signal of optical particle counter (Rion $\mathrm{KC}-03$ ).

Incense sticks were burned inside the fire protector cylinder to maintain burning stability (see Fig. 1). The smoke was then delivered to the aerosol chamber with aerosol flow $\left(Q_{a e r}\right)$. The input airflow $\left(Q_{i n}\right)$ was drawn by a pump $\left(P_{i n}\right)$ and then flowed through the silica gel desiccant, buffer, pressure regulator, and HEPA filter to provide dry, stable, and clean airflow. The aerosol-laden airflow $\left(Q_{a e r}\right)$ to the aerosol chamber was controlled and monitored by the rotameter $\left(\mathrm{R}_{\text {aer }}\right)$ and Flowmeter 2 (Honeywell, AWM5101VN). The dilute airflow $\left(Q_{\text {dil }}\right)$, which was controlled by the rotameter $\left(\mathrm{R}_{\mathrm{dil}}\right)$ and monitored by the Flowmeter 1 (Honeywell, AWM5104VA), was utilized to vary the PM concentration inside the aerosol chamber. The pressure inside the aerosol chamber was kept at ambient pressure by allowing output airflow $\left(Q_{\text {out }}\right)$ to flow through the outlet port on the bottom side of the aerosol chamber. The $Q_{\text {out }}$ took the particles out of the chamber so that the PM concentration decay mainly depended on the value of $Q_{\text {out }}$.

\section{PM Sensors and Reference Monitors}

The aerosol chamber was used to evaluate some commercially available PM sensors, i.e., GP2Y, ZH03, and SDS0. Performance evaluation of the GP2Y sensor has been reported in some literatures (Wang et al., 2015; Sousan et al., 2016; Li and Biswas, 2017; Liu et al., 2017). However, there is no literature presenting those of the ZH03 and SDS0 sensors because they were newly released with limited available information. On the other hand, the SDS0 sensor has very recently been implemented as a PM monitoring device (Khunsongkiet and Boonchieng, 2017; Yang et al., 2017). Therefore, the performance evaluation is necessary to fill the information gap of the sensors.

The pictures and the schematic diagrams of the evaluated PM sensors and HPMA as a reference monitor are shown in Fig. 3 with detailed specifications listed in Table 1. It is seen from Table 1 that the evaluated PM sensors have the advantages in compactness, long lifetime, low-rated current and voltage, and low cost. Although the evaluated PM sensors have less measurement performances (not shown in Table 1) than similar established instruments (e.g., CPC, OPC, TEOM), the specifications provided have potential for industrial applications as air quality detectors in air purifiers, air conditioners, ventilation systems, car air cleaners, and smart home equipment. Moreover, the low voltage and low power of the PM sensors meet the requirement for battery-operated portable air quality monitors.

All of the evaluated PM sensors (SDS0, ZH03, and GP2Y) as well as the HPMA reference monitor utilize scattered light to estimate PM concentration. The sensors mainly consist of particle carrier flow, light source, photodetector, and signal conditioning circuit. The particle carrier flow (usually convective or diffusive flow) transports the particles into a detection area that is marked with dashed circle line in Fig. 3. The HPMA, SDS0, and ZH03 sensors 


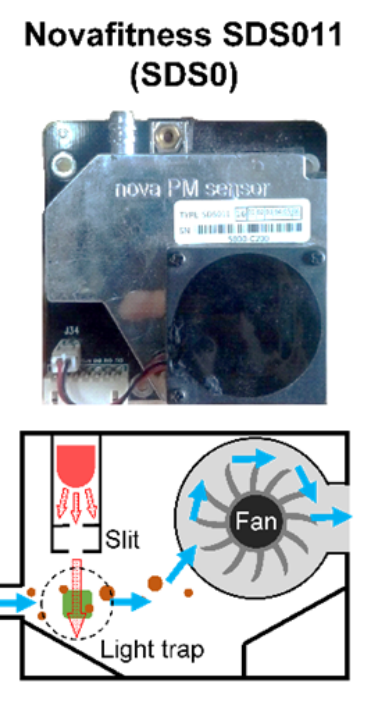

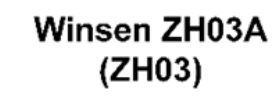
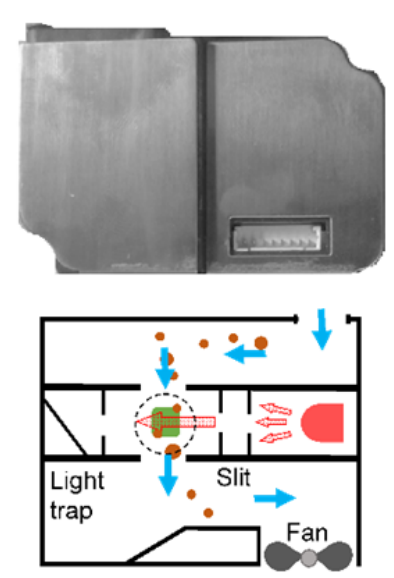

\section{Sharp GP2Y1010AU0F Honeywell HPMA115S0-XXX (GP2Y) \\ (HPMA)}
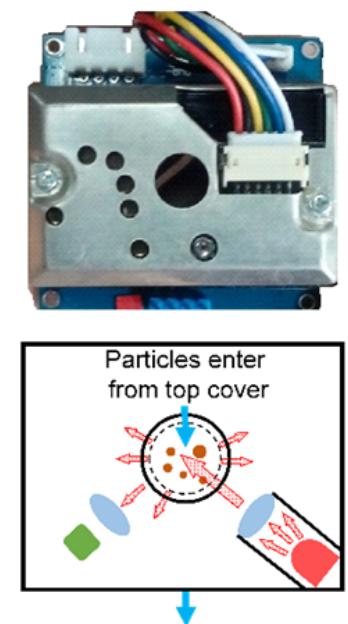
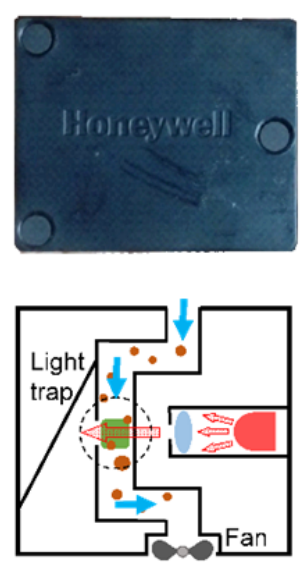

Photodetector

Light source

Lens

$\rightarrow$ Air and particle flow

- Particle

Fig. 3. The picture (top) and diagram (bottom) of the evaluated PM sensors (SDS0, ZH03, and GP2Y) and reference monitor (HPMA).

Table 1. Specifications of HPMA reference monitor and evaluated PM sensors from factory datasheets.

\begin{tabular}{lllll}
\hline Abbreviation & HPMA & SDS0 & ZH03 & GP2Y \\
\hline Model & Honeywell & Novafitness & Winsen & Sharp \\
& HPMA115S0-XXX & SDS011 & ZH03A & GP2Y1010-AU0F \\
\hline Light source & Laser & Laser & Laser & IR-LED \\
Minimum particle size $(\mu \mathrm{m})$ & N/A & 0.3 & 0.3 & N/A \\
Concentration range $\left(\mu \mathrm{g} \mathrm{m}^{-3}\right)$ & $0-1000$ & $0-999.9$ & $0-1000$ & N/A \\
Rated voltage $(\mathrm{V})$ & $5 \pm 0.2$ & $4.7-5.3$ & $5 \pm 0.1$ & $5 \pm 0.5$ \\
Rated current $(\mathrm{mA})$ & $<80$ & $70 \pm 10$ & $<120$ & $<20$ \\
Dimension $\mathrm{W} \times \mathrm{H} \times \mathrm{D}\left(\mathrm{mm}^{3}\right)$ & $43 \times 36 \times 23.7$ & $71 \times 70 \times 23$ & $50 \times 32.4 \times 21$ & $46 \times 30 \times 17.6$ \\
Operating temperature $\left({ }^{\circ} \mathrm{C}\right)$ & -10 to +50 & -20 to +50 & -10 to +50 & -10 to +65 \\
Operating Humidity $(\%)$ & $0-95$ & $0-70$ & $0-85$ & N/A \\
Output signal & Digital & Digital & Digital & Analog \\
Lifetime & 20,000 hours & 8,000 hours & 3 years & NA \\
Cost $(U S D)$ & $\sim \$ 25.84$ & $\sim \$ 25.90$ & $\sim \$ 16.00$ & $\sim \$ 15.13$ \\
\hline
\end{tabular}

use a convective flow from a fan. Other sensors, such as Shinyei PPD42NS and Samyoung DSM501A, use heat that is radiated from a resistor to draw the convective flow (Liu et al., 2017). GP2Y uses random diffusion of the particles for delivering the particles into the detection area. The utilization of the diffusive flow minimizes the need for components, thus reducing both operating power and cost.

Particles in the detection area scatter the light with the intensity proportional to the PM concentration. The scattered light is detected by the photodetector and then processed by the signal conditioning circuit. The angle between the photodetector and the light source varies among the sensors. The GP2Y sensor configures the light source and the photodetector with the angle of $60^{\circ}$ while the SDS0, ZH03, and HPMA sensors with the angle of $90^{\circ}$. A light trap, as can be found in the SDS0, ZH03, and HPMA sensors, prevents the light from reflecting back to the detection area.

The light source is usually an infrared light emitting diode (IR-LED) or laser diode with the addition of a convex lens or slit for focusing the light. The GP2Y sensor uses an IR-LED while the HPMA, SDS0, and ZH03 sensors employ a laser diode as the light source. The IR-LED of GP2Y sensor should be driven by a square wave voltage having the width of $(0.32 \pm 0.02) \mathrm{ms}$ and the period of $(10$ $\pm 1) \mathrm{ms}$. Therefore, a programmed microcontroller module (Arduino, UNO R3) was used for generating the square wave voltage and processing the sensor output signal. Unlike the GP2Y sensor, other PM sensors (SDS0 and ZH03) and the reference monitor (HPMA) have a built-in embedded system to convert and process the photodetector signal into digital data. The PM sensors and the reference monitor were connected to a personal computer (PC) using universal asynchronous receiver/transmitter (UART) communication protocol. A graphical user interface (GUI) application, which was installed in the $\mathrm{PC}$, provided sensor communication and data logging. 


\section{RESULTS AND DISCUSSION}

\section{Aerosol Chamber Characterization \\ PM Concentration Uniformity}

PM concentration uniformity inside the aerosol chamber determines the possibility to place the PM sensors anywhere inside the chamber. To characterize the PM concentration uniformity, six HPMA sensors as reference monitors were placed on all chamber sides (back, front, right, left, top, and bottom sides). Fig. 4 shows PM concentration measurement results on each chamber side. The experimental steps were divided into three regions (A, $\mathrm{B}$, and $\mathrm{C}$ ). Before the experiment, the chamber was cleaned by the dilute airflow $\left(Q_{\text {dil }}\right)$ while the aerosol valve was closed until the PM concentration was near to zero (region A). Then, $\mathrm{PM}_{2.5}$ source from the generator was injected into the chamber by opening the valve until the concentration near the HPMA detection limit $\left(1,000 \mu \mathrm{g} \mathrm{m}^{-3}\right)$ (region A). When the valve was closed, the PM concentration started to decay because the particles were forced out by the output airflow rate $\left(Q_{\text {out }}\right)$, which was equal to $Q_{\text {dil }}$. In some cases, PM inside the chamber needed time to disperse evenly after injection (the peak at region A). Therefore, a transition region (region $\mathrm{B}$ ) was given about $30 \mathrm{~s}$ before the experiment can be started at region $\mathrm{C}$. These procedures were applied to characterize the chamber and evaluate the PM sensors.

Fig. 4 exhibits uniform PM concentration distribution after region $\mathrm{B}$. The difference of $\mathrm{PM}$ concentration on each side was within $10 \%$, which was lower than that obtained by Wang et al. (2015). The PM concentration uniformity inside the chamber can be improved by installing a circulating fan to distribute the particles (Li et al., 2018; Wang et al., 2009; Zhao et al., 2015). In our chamber, the circulating fan was unnecessary because the $Q_{\text {out }}$, which is flowed from the inlet (top side) to the outlet (bottom side), also assisted the particle distribution.

\section{PM Concentration Loss}

In the aerosol chamber, the concentration loss, which has been an unavoidable issue, may be influenced by several mechanisms, i.e., particle coagulation (Rim et al., 2012; Zhao et al., 2015), gravitational precipitation (Wang et al., 2015), and wall deposition (Wang et al., 2014; Manikonda et al., 2016). These mechanisms are size-dependent processes, which may shift the size distribution over time if the particles with wide size distribution are involved (Bowman et al., 1997; Cocker et al., 2001; Wang et al., 2014; Zhao et al., 2015). To maintain the original size distribution profile of the PM source, the experiment should be done in a relatively short time.

Particle coagulation takes significant influence at high particle concentration. For instance, at a particle concentration of $10^{5}-10^{6} \mathrm{pcs} \mathrm{cm}^{-3}$, the mechanism dominates the concentration loss for over 60\% (Zhao et al., 2015). Wall deposition dominates the concentration loss at lower particle concentration (below $2000 \mathrm{pcs} \mathrm{cm}^{-3}$ ) (Zhao et al., 2015). The PM concentration loss can then be described by firstorder kinetics as

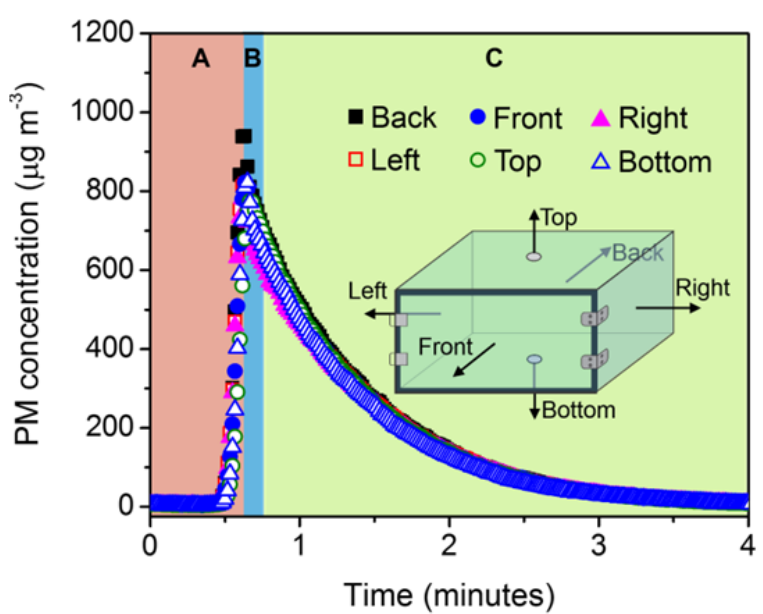

Fig. 4. PM concentration measurement result on all of the chamber sides using the sampling time, $Q_{\text {out }}$, and $V_{C}$ of $5 \mathrm{~s}$, 15.07 $\mathrm{L} \mathrm{min}^{-1}$, and $70.53 \mathrm{~L}$, respectively.

$\frac{d N(t)}{d t}=-\beta N(t)$

Eq. (1) has the following solution

$\frac{N(t)}{N_{0}}=\frac{C(t)}{C_{0}}=\exp (-\beta t)$,

where $N(t)$ is the number of particles, $C(t)$ is the particle or $\mathrm{PM}$ concentration, $\beta$ is the concentration loss coefficient, $t$ is time, and the subscript 0 is the initial condition (Wang et $a l ., 2014)$. The value of $\beta$ is the sum of loss mechanisms (particle coagulation, gravitational precipitation, and wall deposition). However, the influence of each mechanism to the magnitude of $\beta$ is not discussed in this work.

The value of $\beta$ was experimentally obtained by measuring the PM concentration decay at zero $Q_{\text {out }}$. The measurement used the HPMA reference monitor with sampling time of 40 seconds for 650 minutes. Fig. 5 shows the PM concentration decay due to the loss mechanisms, which are compared to the experimental data conducted by Wang et al. (2015). Exponential fit to the experimental data yielded the $\beta$ value of 0.00589 , which was lower than that from the experimental data of Wang et al. (2015). Noting that Wang et al. (2015) used a measuring instrument (SidePak Personal Aerosol Monitor AM510) with relatively high inlet airflow rate $\left(0.7 \mathrm{~L} \mathrm{~min}^{-1}\right)$, the concentration loss might be dominated by instrument inlet airflow than the concentration loss mechanisms.

\section{PM Concentration Decay in the Aerosol Chamber}

The PM concentration decay rate inside the aerosol chamber was intended to be controlled by the setting of $Q_{\text {out }}$ instead of the loss mechanisms. A simple equation can be derived to describe the PM concentration decay profile inside the aerosol chamber. Let the particles with an initial concentration of $C_{0}$ are introduced into a chamber with volume of $V_{C}$. The particles are taken out by a constant 


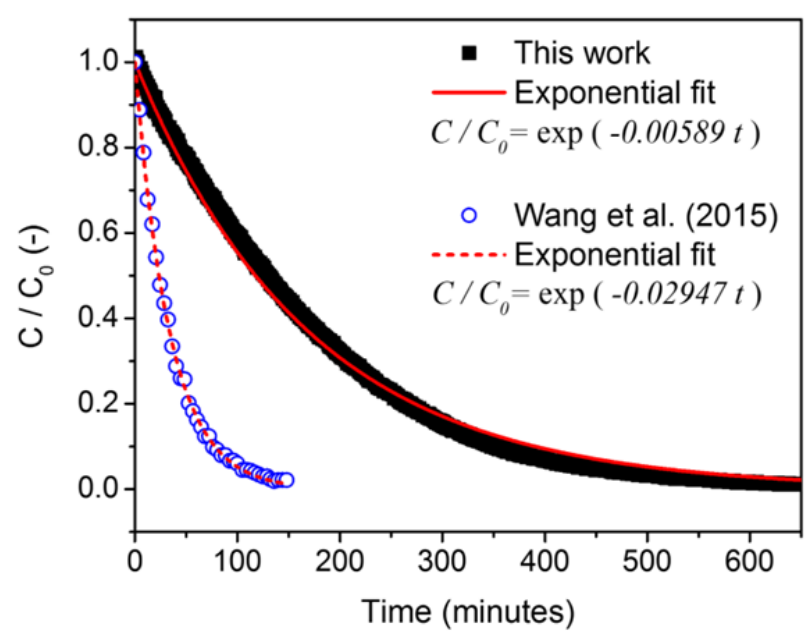

Fig. 5. A comparison between the PM concentration decay obtained from the present experiment $\left(V_{C}=70.53 \mathrm{~L}\right)$ and that measured by Wang et al. (2015) $\left(V_{C}=94.19 \mathrm{~L}\right)$.

output airflow rate of $Q_{\text {out }}$ so that the number of particles inside the chamber $(N(t))$ can be expressed as

$$
\frac{d N(t)}{d t}=N_{\text {in }}(t)-N_{\text {out }}(t)-N_{\text {loss }}(t)
$$

where $N_{\text {in }}(t)$ and $N_{\text {out }}(t)$ are the number of particles injected into and taken out from the chamber, respectively, $N_{\text {loss }}(t)$ is the total particle loss due to the concentration loss mechanisms (Chen et al., 2017). If no new particles are introduced into the chamber after region B (see Fig. 4), Eq. (3) can be simplified as

$$
\frac{d N(t)}{d t}=-N_{\text {out }}(t)-N_{\text {loss }}(t)
$$

Based on Fig. 4, we can assume that the particles are distributed evenly inside the aerosol chamber so that the PM concentration $C(t)$ is always the same at any point. Therefore, the number of particles exiting the chamber is equal to $\alpha Q_{\text {out }} C(t)$ or at a constant chamber volume is $\alpha Q_{\text {out }}\left(N(t) / V_{C}\right)$, where $\alpha$ is a flow to volume coefficient. The coefficient was introduced into the equation because the chamber shapes, such as cubical, cylindrical, or spherical, may affect the concentration decay rate. Moreover, the total particle loss $\left(N_{\text {loss }}(t)\right)$ is proportional to $\beta$. Then, Eq. (4) becomes

$$
\frac{d N(t)}{d t}=-\frac{\alpha Q_{\text {out }} N(t)}{V_{C}}-\beta N(t)
$$

Eq. (5) has the following solution

$$
\frac{N(t)}{N_{0}}=\frac{C(t)}{C_{0}}=\exp \left[-\left(\alpha \frac{Q_{\text {out }}}{V_{C}}+\beta\right) t\right]=\exp \left(-\alpha \frac{Q_{\text {out }}}{V_{C}} t\right) \exp (-\beta t)
$$

Eq. (6) describes the PM concentration decay inside the aerosol chamber by $Q_{\text {out }}$ and the concentration loss mechanisms.

To prove Eq. (6), the experiments of PM concentration decay were carried out by varying the chamber volume $\left(V_{C}\right)$ and output airflow rate $\left(Q_{\text {out }}\right)$. The initial effective chamber volume (empty chamber volume subtracted by the volume of components inside the chamber) was $70.53 \mathrm{~L}$. The effective chamber volume was decreased by adding styrofoam sheets with different thickness on the top side of the chamber. The effective chamber volume $\left(V_{C}\right)$ could be varied to $70.53,65.50,55.44,42.03$, and $28.62 \mathrm{~L}$. The time series measurement by using the HPMA reference monitor at $Q_{\text {out }}$ of $10.06 \mathrm{~L} \mathrm{~min}^{-1}$ with varied $V_{C}$ is shown in Fig. 6. The results led to an exponential equation with a different exponential coefficient $(B)$ for each $V_{C}$ value. The inset in Fig. 6 exhibits the graph of $B$ over $V_{C}$ having an inverse relation $\left(B \propto 1 / V_{C}\right)$. However, the value of $\alpha$ was not determined from Fig. 6 since the power regression of the graph had a low $\mathrm{R}^{2}$ of 0.9544 .

Fig. 7 is the PM concentration decay at the varied $Q_{o u t}$ of $2.14,5.27,10.06$, and $15.07 \mathrm{~L} \mathrm{~min}^{-1}$ using a constant $V_{C}$ of $70.53 \mathrm{~L}$. The decay equations have different coefficient $A$ at different $Q_{\text {out }}$. By applying a linear fit to $A$ over $Q_{\text {out }} / V_{C}$ and taking $\beta$ value into account $(\beta=0.00589$ from the previous experiment), the value of $\alpha$ was obtained to be 1.01376 as shown in the inset of Fig. 7. Therefore, an empirical equation to describe the PM concentration decay profile as a function of time $(t)$, output flow rate $\left(Q_{o u t}\right)$, and chamber volume $\left(V_{C}\right)$ can be written as

$$
\frac{C(t)}{C_{0}}=\exp \left[-1.01376 \frac{Q_{\text {out }}}{V_{C}} t\right] \exp (-0.00589 t)
$$

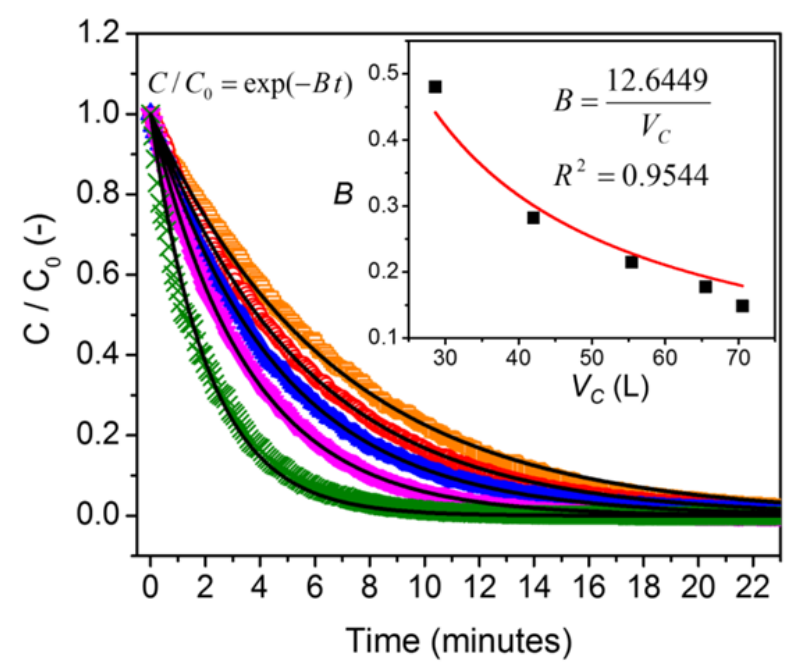

Fig. 6. $P M$ concentration decays at various chamber effective volumes $\left(V_{C}\right)$ of $70.53(-\square-), 65.50(-\circ-), 55.44$ $\left(-\boldsymbol{\Delta}_{-}\right), 42.03(-\nabla-)$, and $28.62\left(-x_{-}\right) \mathrm{L}$ at a constant output flow rate $\left(Q_{\text {out }}\right)$ of $10.06 \mathrm{~L} \mathrm{~min}^{-1}$. Exponential fit (black line) was applied to the PM concentration decay. Exponential coefficient vs. $V_{C}$ (-口-) depicted an inverse relation as shown in inset. 


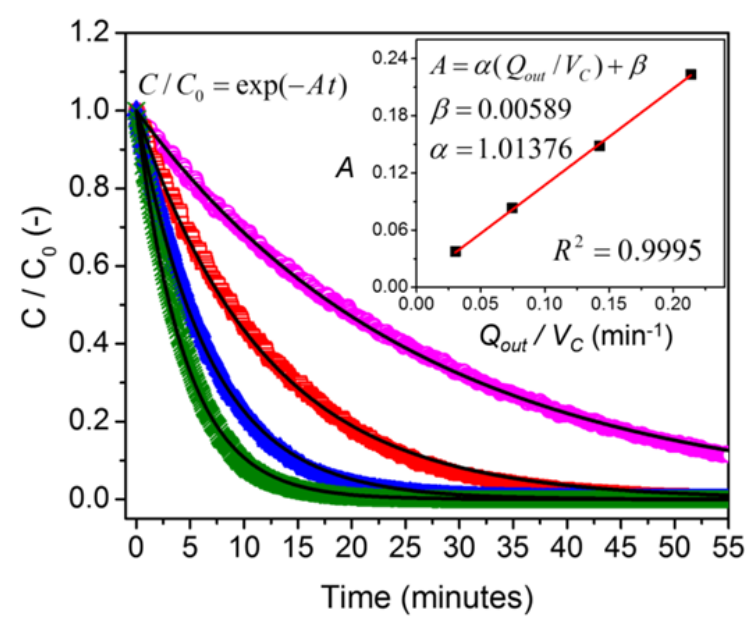

Fig. 7. PM concentration decay at various output flow rates $\left(Q_{\text {out }}\right)$ of $2.14(-\circ-), 5.27(-\square-), 10.06(-\mathbf{\Delta}-)$, and $15.07\left(-x_{-}\right) \mathrm{L} \mathrm{min}^{-1}$ at a constant chamber volume $\left(V_{C}\right)$ of $70.53 \mathrm{~L}$. Exponential fit (black line) was applied to each $Q_{\text {out }}$ variation. The inset shows linear fit (red line), which was applied to exponential coefficient vs. $Q_{\text {out }} / V_{C}$ data (-匹-).

\section{The i-life of PM Concentration Decay and the Number of Data Points}

To predict the number of data points from the experiment, an $i$-life quantity $\left(t_{i}\right)$ is defined as the time required for the PM concentration to decay to an $i$ of its initial concentration with $0<i<1$. From Eq. (6), $i$-life $\left(t_{i}\right)$ can be derived as follows

$t_{i}=-\frac{\ln (i)}{\left(\alpha Q_{\text {out }} / V_{C}+\beta\right)}$.

Fig. 8 gives experimental results of the PM concentration decay $\left(V_{C}=65.50 \mathrm{~L}\right.$ and $\left.Q_{\text {out }}=10.06 \mathrm{~L} \mathrm{~min}^{-1}\right)$, which was compared to Eq. (6) at ideal condition $(\alpha=1$ and $\beta=0)$ and empirical equation ( $\alpha=1.01376$ and $\beta=0.00589)$. The comparison of $i$-life between the ideal and empirical equations for $i=1 / 20\left(t_{1 / 20}\right)$ exhibited an error to experimental data as summarized in Table 2.

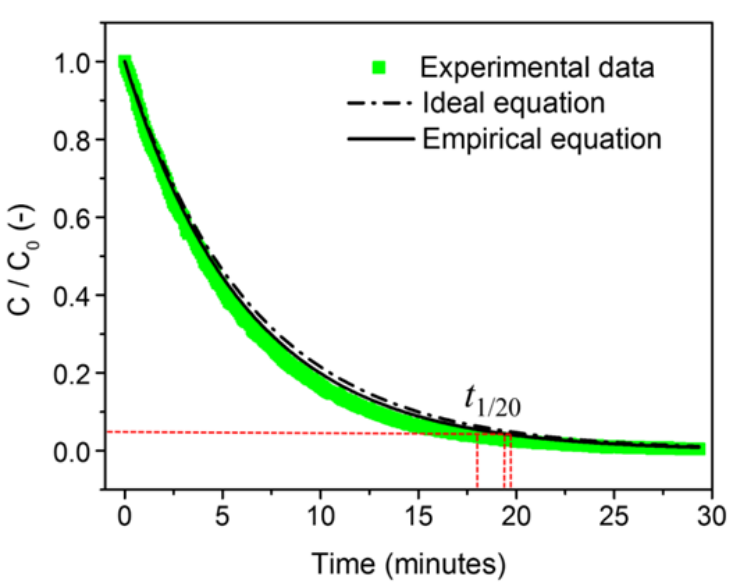

Fig. 8. The comparison of PM concentration decay from the experimental data, ideal equation, and the empirical equation for $V_{C}$ and $Q_{\text {out }}$ of $65.50 \mathrm{~L}$ and $10.06 \mathrm{~L} \mathrm{~min}^{-1}$, respectively.

The number of data points $\left(N_{\mathrm{i}}\right)$ that will be obtained from the experiment can be derived as follows:

$N_{i}=\frac{t_{i}}{t_{s}}=-\frac{\ln (i)}{\left(\alpha Q_{\text {out }} / V_{C}+\beta\right) . \mathrm{t}_{s}}$,

where $t_{s}$ is the sampling time of the measuring instruments. The prediction of the number of data points is important before undergoing the experiment. The output airflow rate $\left(Q_{\text {out }}\right)$ can effectively decrease the experiment time, but as a result, the number of data points will be fewer. Note that the PM concentration measurement instruments have sampling times varying from a second to minutes. Therefore, the experimental parameters $\left(V_{C}, Q_{\text {out }}\right.$, and $\left.t_{s}\right)$ should be considered so that the number of data points are large enough for better analysis.

Table 2 lists the number of data points $\left(N_{i}\right)$ with $i=$ $1 / 20$, which were obtained from the experimental data or calculated using Eq. (9) with $\alpha=1$ and $\beta=0$ (ideal equation) or $\alpha=1.01376$ and $\beta=0.00589$ (empirical equation). The empirical equation gave the $N_{1 / 20}$ value with smaller

Table 2. Comparison of $t_{1 / 20}$ and $N_{1 / 20}$ values obtained from experimental data (Exp.), theoretical equation (Ideal), and empirical equation (Empiric) for various chamber volumes and output flow rates.

\begin{tabular}{|c|c|c|c|c|c|c|c|c|c|}
\hline \multirow{2}{*}{$\begin{array}{l}V_{C} \\
\text { (L) }\end{array}$} & \multirow{2}{*}{$\begin{array}{l}Q_{\text {out }} \\
\left(\mathrm{L} \min ^{-1}\right)\end{array}$} & \multicolumn{3}{|c|}{$t_{1 / 20}$ (minute) } & \multicolumn{3}{|c|}{$* N_{1 / 20}$} & \multicolumn{2}{|c|}{$* * N_{1 / 20}$ relative error $(\%)$} \\
\hline & & Exp. & Ideal & Empiric & Exp. & Ideal & Empiric & Ideal & Empiric \\
\hline 70.53 & 0 & 450 & NA & 508.6 & 5402 & NA & 6103 & NA & 12.98 \\
\hline 70.53 & 2.14 & 74.4 & 98.7 & 81.7 & 893 & 1185 & 981 & 32.70 & 9.85 \\
\hline 70.53 & 5.27 & 33.3 & 40.1 & 36.7 & 400 & 481 & 440 & 20.25 & 10.00 \\
\hline 70.53 & 15.07 & 12.2 & 14.0 & 13.5 & 147 & 168 & 162 & 14.28 & 10.20 \\
\hline 70.53 & 10.06 & 20.0 & 21.0 & 19.9 & 240 & 252 & 239 & 5.00 & 0.42 \\
\hline 65.50 & 10.06 & 16.4 & 19.5 & 18.5 & 197 & 234 & 222 & 18.78 & 12.69 \\
\hline 55.44 & 10.06 & 13.6 & 16.5 & 15.8 & 163 & 198 & 189 & 21.47 & 15.95 \\
\hline 42.03 & 10.06 & 10.8 & 12.5 & 12.0 & 129 & 150 & 145 & 16.28 & 12.40 \\
\hline \multicolumn{5}{|c|}{ Average relative error $(\%)$} & & & & 18.39 & 10.22 \\
\hline
\end{tabular}

* $N_{1 / 20}$ was rounded to the closest integer value.

** $N_{1 / 20}$ relative error was calculated relative to the experimental results. 
average error $(10.22 \%)$ than that with the ideal equation (18.39\%). The prediction of $N_{i}$ by Eq. (9) would have smaller error if the particle loss due to the inlet airflow of measuring instruments, in this case HPMA, CPC, and the evaluated PM sensors, were taken into account.

\section{Evaluation of PM Sensors}

Experimental Parameters for Evaluation of PM Sensors

The PM sensors were evaluated in the aerosol chamber using $V_{C}, Q_{o u t}$, and $t_{s}$ of $70.53 \mathrm{~L}, 10.06 \mathrm{~L} \mathrm{~min}^{-1}$, and $5 \mathrm{~s}$, respectively. These experimental parameters resulted in $t_{1 / 20}$ less than 20 minutes (see Table 2), which was faster than undergoing the experiment and only relied on the concentration loss mechanisms to decay the PM concentration. The number of data points $\left(N_{l / 20}\right)$ calculated using Eq. (9) yielded 239 data points, which were quite large for a relatively short experiment time.

Fig. 9 shows the PM concentration decay that was measured by the evaluated PM sensors (SDS0, ZH03, GP2Y) and reference monitors (HPMA and CPC). The data were fully recorded in three regions (A, B, and $\mathrm{C}$ ), but only the data in region $\mathrm{C}$ were taken for further analysis. The number of data points $\left(N_{1 / 20}\right)$ obtained from the experiment was 240, which were close to the prediction obtained by Eq. (9). The HPMA reference monitor as well as the SDS0 and ZH03 sensors represent the particle mass concentration in digital data with the measurement limit of about $1,000 \mu \mathrm{g} \mathrm{m}^{-3}$. The GP2Y sensor represents the particle mass concentration as analog voltage with higher measurement limit of about 3,000 $\mathrm{g} \mathrm{m}^{-3}$ (Wang et al., 2015).

\section{Linearity of PM Sensors}

The linearity of PM sensors was analyzed by applying a linear fit to the measurement data obtained by the evaluated PM sensors and reference monitors. A pairwise correlation was then employed to the fitting coefficient of determination $\left(\mathrm{R}^{2}\right)$. Fig. 10 shows the pairwise correlation of the evaluated PM sensors and the reference monitors. The pairwise correlation of the evaluated PM sensors to the reference monitors has the $\mathrm{R}^{2}$ higher than 0.956 . The pairwise correlation of the GP2Y sensor showed a relatively high $\mathrm{R}^{2}(>0.95)$, which was close to that obtained by the previous studies (Wang et al., 2015; Sousan et al., 2016). However, the $\mathrm{R}^{2}$ of the GP2Y sensor was slightly smaller, compared to those of the SDS0 and ZH03 sensors. The SDS0 sensor outperformed the linearity with $\mathrm{R}^{2}>0.994$.

The low linearity of the GP2Y sensor compared to those of the SDS0 and ZH03 sensors may be caused by the difference of particle delivery. The original GP2Y sensor only relies on the diffusive movement of particles for transporting the particles into the sensor detection area. On the other hand, both the SDS0 and ZH03 sensors have a built-in fan for particles transport. A commercial PM monitor, such as TSI-AirAssure $\mathrm{PM}_{2.5}$ Indoor Air Quality Monitor, modifies the GP2Y sensor by adding a regulated airflow system for the particle delivery (Wang et al., 2015). Wang et al. (2015) conducted a performance comparison between the original GP2Y sensor and the airflow-assisted GP2Y sensor and they showed that the particle transport provided by a regulated airflow improved the linearity. Moreover, the particles movement due to random diffusion is relatively slow and may cause low sensor response to the changes of PM concentration. This leads to the existence of erratically distributed particles inside the detection area and the measurement error then takes place (Wang et al., 2015). The utilization of a fan in the SDS0 and ZH03 sensors minimizes the diffusion influences on the particle transport and thus improves the overall sensor performance.

Fig. 11 gives four repetitive measurement results obtained using the evaluated PM sensors (SDS0, ZH03, GP2Y), which were compared to the HPMA reference monitor as particle mass concentration reference and the CPC as particle number concentration reference. Noting that the CPC measured particle number concentration while the PM sensors and HPMA reference monitor measured the particle mass concentration, a direct comparison between them cannot be applied. The particle mass concentration can be calculated from the particle number concentration if particle size distribution and density are known (Li and Biswas, 2017). Fig. 11 also shows the average data of four measurement results and a linear fit was applied to the average data. The figure exhibits curvatures so that the

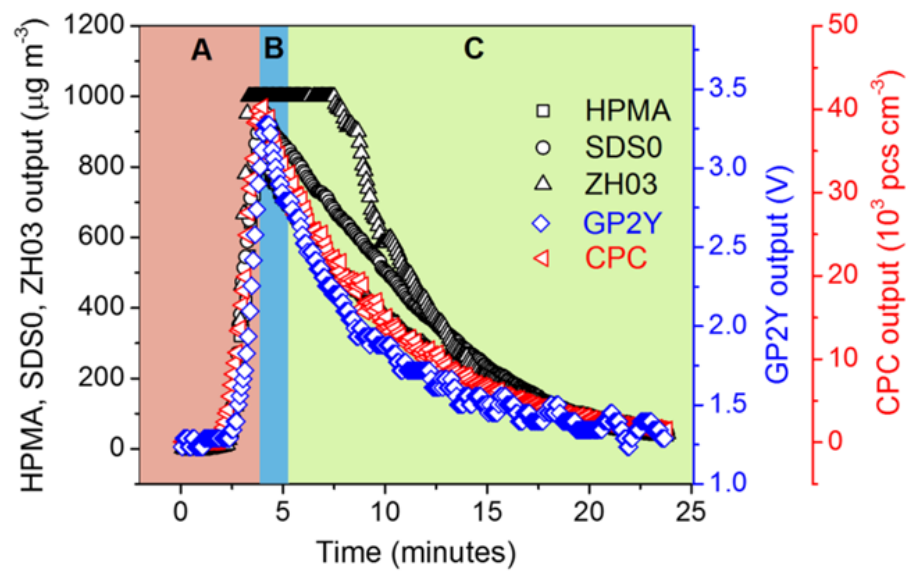

Fig. 9. Time series PM concentration, which was measured by the evaluated PM sensors (SDS0, ZH03, GP2Y) and reference monitors (HPMA and CPC) using $V_{C}, Q_{\text {out }}$, and $t_{s}$ of $70.53 \mathrm{~L}, 10.06 \mathrm{~L} \mathrm{~min}^{-1}$, and $5 \mathrm{~s}$, respectively. 


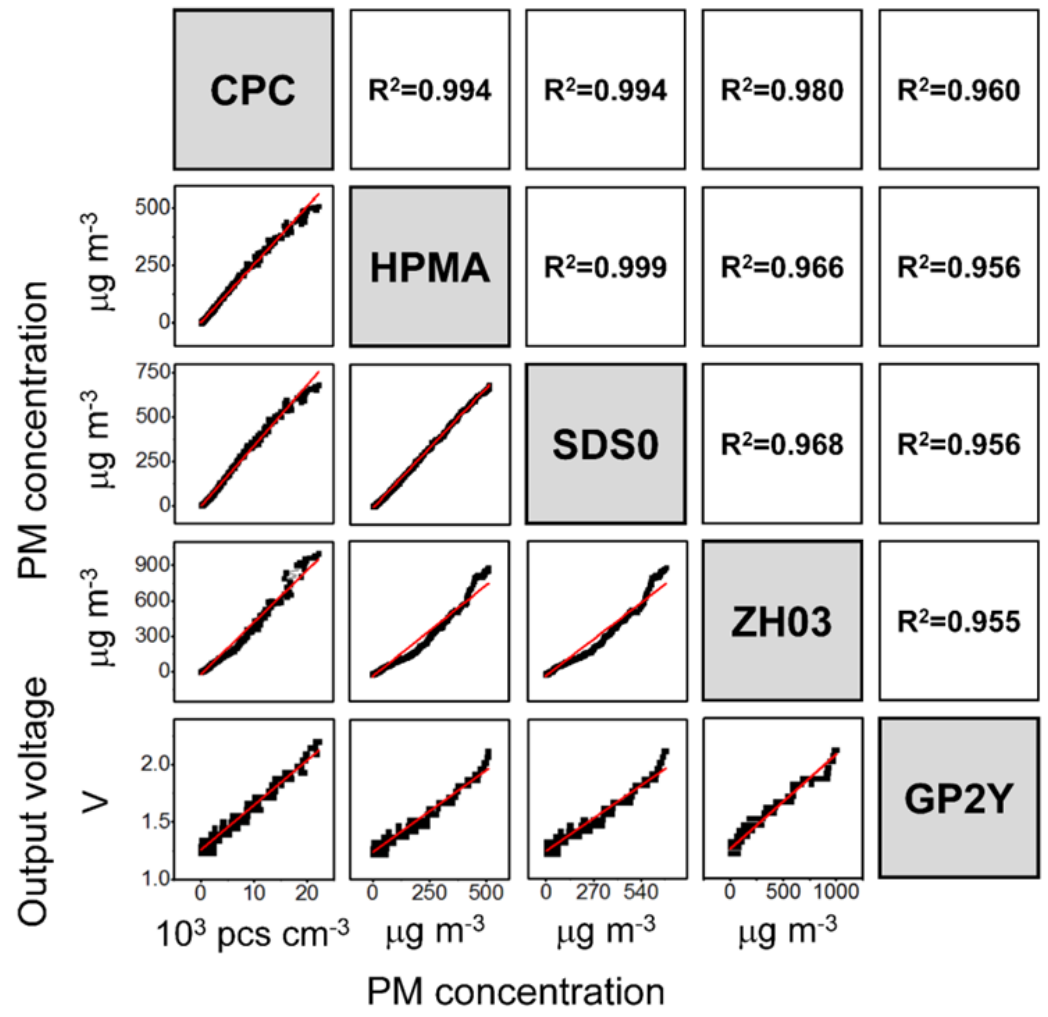

Fig. 10. Pairwise correlation among the evaluated PM sensors and reference monitors using $V_{C}, Q_{o u t}$, and $t_{s}$ of $70.53 \mathrm{~L}$, $10.06 \mathrm{~L} \mathrm{~min}^{-1}$, and $5 \mathrm{~s}$, respectively.

linearity of the evaluated PM sensors depends on the PM concentration range. As a result, least square regression was done at two PM concentration ranges of $0-700 \mu \mathrm{g} \mathrm{m}^{-3}$ and $0-400 \mu \mathrm{g} \mathrm{m}^{-3}$ and the results are tabulated in Table 3 . The measurement range of $0-400 \mu \mathrm{g} \mathrm{m}^{-3}$ is used in commercial PM monitoring devices (Sousan et al., 2017). The values of $\mathrm{R}^{2}$ of the SDS0 and GP2Y sensors at the concentration range of $0-400 \mu \mathrm{g} \mathrm{m}^{-3}$ were higher than those for $0-700 \mu \mathrm{g} \mathrm{m}^{-3}$. In contrast, the $\mathrm{ZH} 03$ sensor gave smaller $\mathrm{R}^{2}$ for the concentration range of $0-400 \mu \mathrm{g} \mathrm{m}^{-3}$ because the curvature still existed within this range (see Figs. 11(c) and 11(d)). The best linearity of the ZH03 sensor was obtained at lower PM concentration (below $200 \mu \mathrm{g} \mathrm{m}^{-3}$ ), which gave the $\mathrm{R}^{2}$ of 0.994 . The low measurement range of the $\mathrm{ZH} 03$ sensor can be an issue for applications in the highly polluted areas, such as industrial sites, heavy traffic roads, and volcanoes. Nevertheless, the measurement range below $200 \mu \mathrm{g} \mathrm{m}^{-3}$ can be used for a specific applications, such as indoor and outdoor $\mathrm{PM}_{2.5}$ monitoring systems in an urban neighborhood, in which the concentration is usually below $100 \mu \mathrm{g} \mathrm{m}^{-3}$ (Ramachandran et al., 2003).

In Fig. 11, the measurement results obtained from the evaluated PM sensors were set as dependent variable while the measurement results performed by the HPMA reference monitor were set as independent variable. However, the PM concentration measured by the HPMA reference monitor may have uncertainty as shown in Figs. 12(a) and 12(b). Therefore, a reduced major axis (RMA) regression was applied and the result was tabulated in Table 3 . The
RMA is more appropriate to determine linearity for this case because it considers the error on both dependent and independent variables (Wang et al., 2015). The difference between RMA and least square regression results was relatively small, which indicated small influence or variation in the PM concentration measured by the HPMA reference monitor. The small variation on the PM concentration measurement result of the HPMA reference monitor was proven by the repetitive measurement results in Fig. 12(a) with the standard deviation and coefficient of variation shown in Fig. 12(b). The PM concentration measured by the HPMA reference monitor had the standard deviation and coefficient of variation of $7.78 \mu \mathrm{g} \mathrm{m}^{-3}$ and $3.68 \%$, respectively.

\section{Calibration Curves of PM Sensors}

An ideal sensor has a linear relationship between its input and output. For this case, all of the evaluated PM sensors showed a linear relation at specific and small PM concentration range. The curvature, which existed at the broader range, tended to have a second-order polynomial relation. The polynomial regression coefficients of the measurement results in Fig. 11 are tabulated in Table 4. The second-order polynomial regression gave the higher $\mathrm{R}^{2}$ than that of the linear regression at the PM concentration range of $0-700 \mu \mathrm{g} \mathrm{m}^{-3}$ for all of the evaluated PM sensors.

The selection of second order polynomial equation for determining calibration curve was merely empirically based on the best fit. The exact physical processes that lead to the curve trend was still unknown. Dacunto et al. (2015) 
derived a more general form of calibration curve between the sensor and monitor. The calibration curve was derived by taking the decay equation from the sensor and monitor.
All of the evaluated PM sensors (see Fig. 11) have a similar decay form so that the decay parameters of each sensor (initial value and decay coefficient) can be defined.

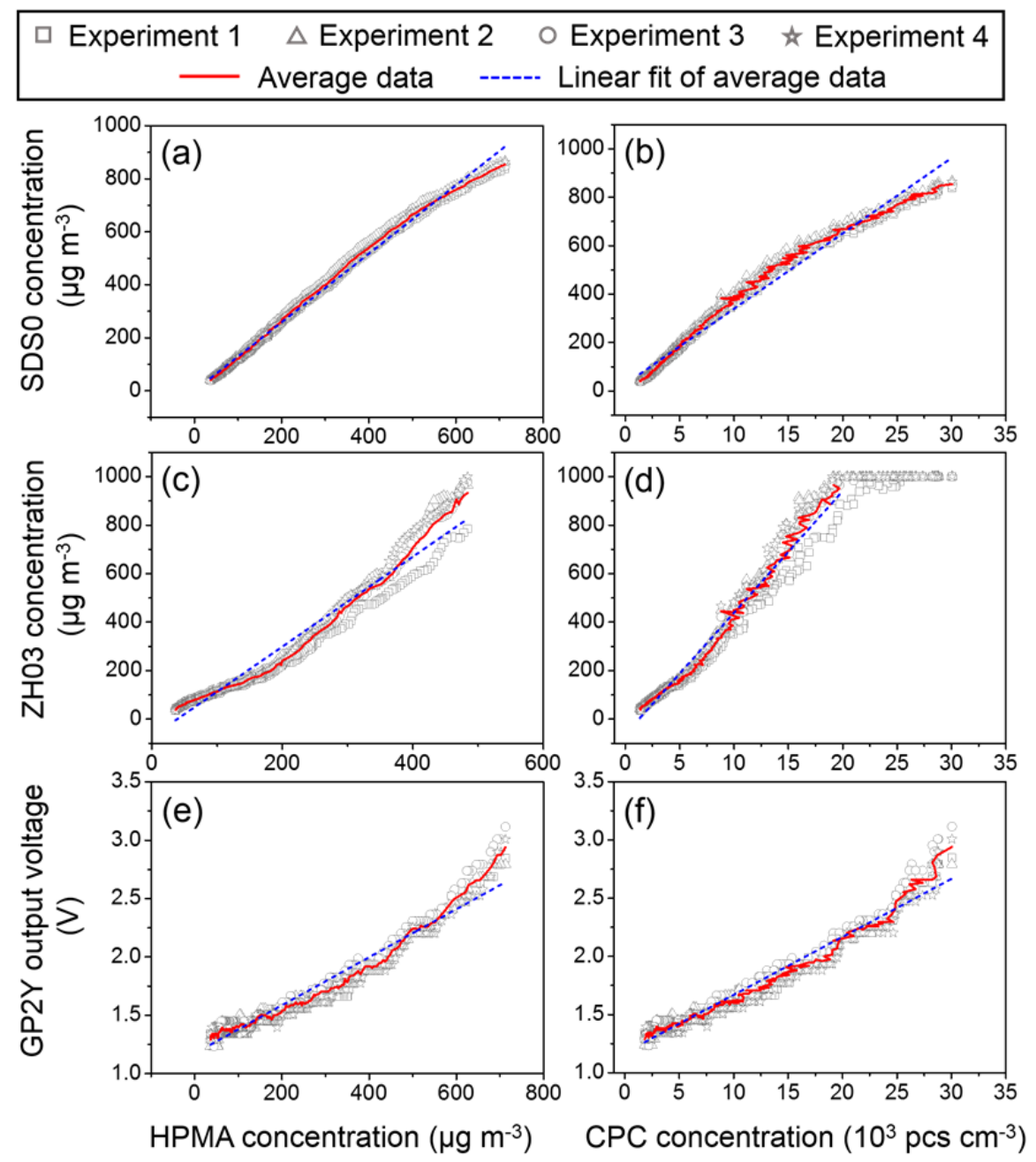

Fig. 11. Pairwise correlation from four repetitive measurements using the evaluated PM sensors (SDS0, ZH03, and GP2Y) compared to the reference monitors (HPMA and CPC): (a) SDS0 vs. HPMA, (b) SDS0 vs. CPC, (c) ZH03 vs. HPMA, (d) ZH03 vs. CPC, (e) GP2Y vs. HPMA, and (f) GP2Y vs. CPC.

Table 3. The least square and reduced major axis (RMA) regression of the evaluated PM sensors compared to the HPMA and CPC reference monitors for the PM concentration range of $0-700 \mu \mathrm{g} \mathrm{m}^{-3}$ and $0-400 \mu \mathrm{g} \mathrm{m}^{-3}$.

\begin{tabular}{|c|c|c|c|c|c|c|c|c|c|c|c|c|}
\hline \multicolumn{13}{|c|}{ Particle Mass Concentration (HPMA as reference) } \\
\hline \multirow{3}{*}{ Sensors } & \multirow{2}{*}{\multicolumn{3}{|c|}{$\begin{array}{c}\text { Least squares } \\
\left(0-700 \mu \mathrm{g} \mathrm{m}^{-3}\right)\end{array}$}} & \multirow{2}{*}{\multicolumn{3}{|c|}{$\frac{\text { RMA }}{\left(0-700 \mu \mathrm{g} \mathrm{m}^{-3}\right)}$}} & \multirow{2}{*}{\multicolumn{3}{|c|}{$\begin{array}{c}\text { Least squares } \\
\left(0-400 \mu \mathrm{g} \mathrm{m}^{-3}\right) \\
\end{array}$}} & \multirow{2}{*}{\multicolumn{3}{|c|}{$\begin{array}{l}\text { RMA } \\
\left.-400 \mu \mathrm{g} \mathrm{m}^{-3}\right) \\
\end{array}$}} \\
\hline & & & & & & & & & & & & \\
\hline & Intercept & Slope & $\mathrm{R}^{2}$ & Intercept & Slope & $\mathrm{R}^{2}$ & Intercept & Slope & $\mathrm{R}^{2}$ & Intercept & Slope & $\mathrm{R}^{2}$ \\
\hline SDS0 & -0.134 & 1.294 & 0.9956 & 0.043 & 0.940 & 0.9980 & -15.045 & 1.394 & 0.9996 & 0.105 & 0.909 & 0.9995 \\
\hline $\mathrm{ZH} 03$ & -56.501 & 1.769 & 0.9701 & 0.213 & 0.855 & 0.9860 & -48.675 & 1.664 & 0.96 & 0.141 & 0.891 & 0.9823 \\
\hline GP2Y & 1.172 & 0.002 & 0.9641 & 1.172 & 4.143 & 0.8232 & 1.250 & 0.002 & 0.9798 & 0.929 & 6.792 & 0.8832 \\
\hline \multicolumn{13}{|c|}{ Particle Number Concentration (CPC as reference) } \\
\hline \multirow{3}{*}{ Sensors } & \multicolumn{3}{|c|}{ Least squares } & \multirow{2}{*}{\multicolumn{3}{|c|}{$\frac{\text { RMA }}{\left(0-29000 \mathrm{pcs} \mathrm{cm}^{-3}\right)}$}} & \multicolumn{3}{|c|}{ Least squares } & \multicolumn{3}{|c|}{ RMA } \\
\hline & \multicolumn{3}{|c|}{$\left(0-29000 \mathrm{pcs} \mathrm{cm}^{-3}\right)$} & & & & \multicolumn{3}{|c|}{$\left(0-15000 \mathrm{pcs} \mathrm{cm}^{-3}\right)$} & \multicolumn{3}{|c|}{$\left(0-15000 \mathrm{pcs} \mathrm{cm}^{-3}\right)$} \\
\hline & Intercept & Slope & $\mathrm{R}^{2}$ & Intercept & Slope & $\mathrm{R}^{2}$ & Intercept & Slope & $\mathrm{R}^{2}$ & Intercept & Slope & $\mathrm{R}^{2}$ \\
\hline SDS0 & 28.211 & 31.138 & 0.9797 & -1.460 & 0.968 & 0.9892 & -10.616 & 38.427 & 0.9947 & -1.303 & 0.891 & 0.9954 \\
\hline ZH03 & -19.838 & 42.800 & 0.9633 & -1.283 & 0.881 & 0.9896 & -45.527 & 46.252 & 0.9779 & -1.267 & 0.873 & 0.9889 \\
\hline GP2Y & 1.208 & 0.051 & 0.9838 & -0.101 & 4.215 & 0.8632 & 1.253 & 0.042 & 0.9837 & -0.498 & 6.686 & 0.9042 \\
\hline
\end{tabular}




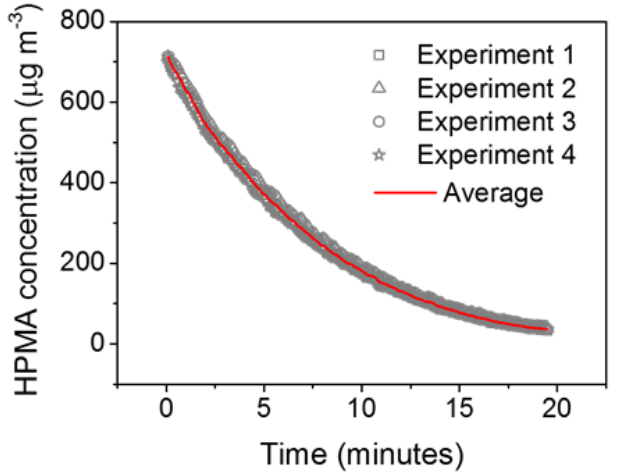

(a)

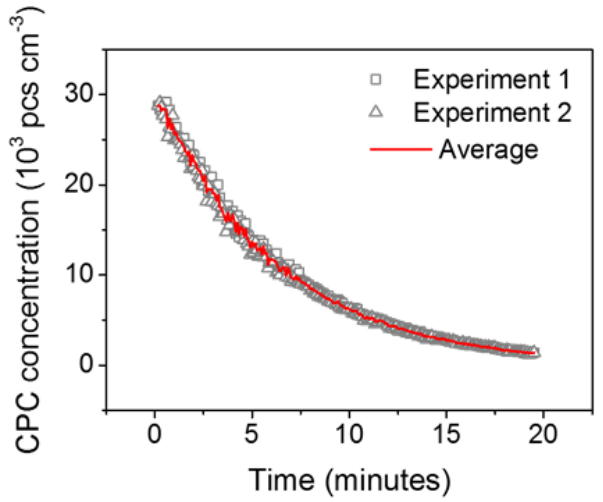

(c)

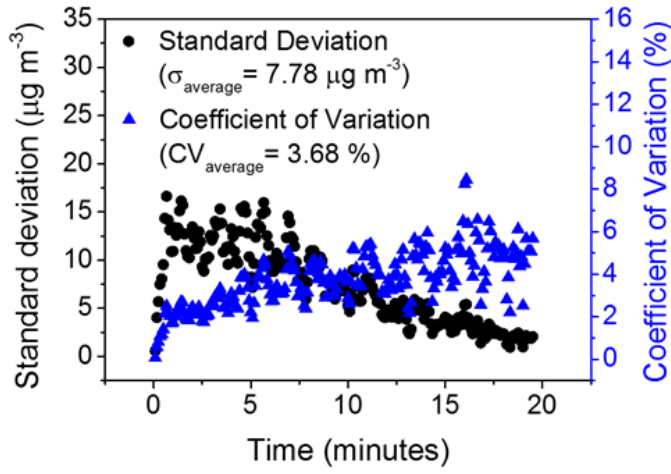

(b)

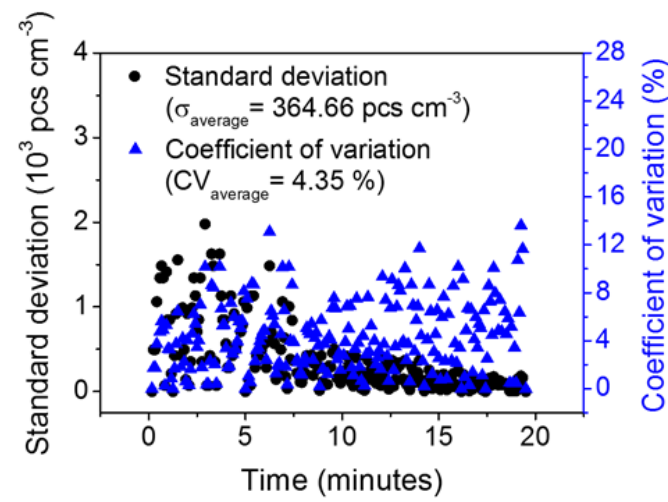

(d)

Fig. 12. Time series PM concentration measured by (a) HPMA and (c) CPC as well as the comparison of standard deviation and coefficient of variation from (b) HPMA and (d) CPC.

Table 4. The power fit and second order polynomial fit of the measurement data in Fig. 11.

\begin{tabular}{|c|c|c|c|c|c|c|c|}
\hline \multicolumn{8}{|c|}{ Particle Mass concentration $\left(0-700 \mu \mathrm{g} \mathrm{m}^{-3}\right)$} \\
\hline \multirow{2}{*}{ Sensors } & \multicolumn{3}{|c|}{ Power fit $\left(y=m x^{\mathrm{n}}\right)$} & \multicolumn{4}{|c|}{ second order polynomial fit $\left(y=a x^{2}+b x+c\right)$} \\
\hline & $\mathrm{m}$ & $\mathrm{n}$ & $\mathrm{R}^{2}$ & $\mathrm{a}$ & $\mathrm{b}$ & $\mathrm{c}$ & $\mathrm{R}^{2}$ \\
\hline SDS0 & 1.541 & 0.971 & 0.9961 & $-4.44 \times 10^{-4}$ & 1.580 & -27.676 & 0.9992 \\
\hline ZH03 & 0.128 & 1.437 & 0.9944 & 0.003 & 0.590 & 23.308 & 0.9982 \\
\hline GP2Y & NA & NA & NA & $2.22 \times 10^{-6}$ & $6.47 \times 10^{-4}$ & 1.31 & 0.9970 \\
\hline \multicolumn{8}{|c|}{ Particle Number concentration $\left(0-29000 \mathrm{pcs} \mathrm{cm}^{-3}\right)$} \\
\hline \multirow{2}{*}{ Sensors } & \multicolumn{3}{|c|}{ Power fit $\left(y=m x^{\mathrm{n}}\right)$} & \multicolumn{4}{|c|}{ second order polynomial fit $\left(y=a x^{2}+b x+c\right)$} \\
\hline & $\mathrm{m}$ & $\mathrm{n}$ & $\mathrm{R}^{2}$ & $\mathrm{a}$ & $\mathrm{b}$ & $\mathrm{c}$ & $\mathrm{R}^{2}$ \\
\hline SDS0 & 48.181 & 0.869 & 0.9894 & -0.563 & 46.185 & -29.825 & 0.9984 \\
\hline $\mathrm{ZH} 03$ & 21.496 & 1.285 & 0.9934 & 1.026 & 31.315 & -8.086 & 0.9929 \\
\hline GP2Y & NA & NA & NA & $9.93 \times 10^{-4}$ & 0.022 & 1.287 & 0.9931 \\
\hline
\end{tabular}

The decay equation from an evaluated PM sensor and a reference monitor can be written as

$x=G \exp (-g t), \quad y=H \exp (-h t)$

where $x$ and $y$ are the responses of the sensor and monitor, respectively, $G$ and $H$ are the initial values of the sensor and monitor, respectively, $g$ and $h$ are the decay coefficients of the sensor and monitor, respectively, and $t$ is time. Solving two equations above by eliminating $t$ yields

$y=\left(H G^{-h / g}\right) x^{h / g}$, or can be simplified to

$y=m x^{n}$,

where $m$ and $n$ are the calibration curve parameters (Dacunto et al., 2015). Eq. (12) shows the calibration curve with a power relation. The calibrations of the evaluated PM sensors to reference monitors by Eq. (12) are tabulated in Table 4. Although some power fit results had lower $\mathrm{R}^{2}$ compared to those obtained by linear or polynomial fit, the power relation in Eqs. (11)-(12) can be used for determining aerosol aging from common aerosol sources (Dacunto et al., 2015). 
The calibration curves of the evaluated PM sensors can have many equation forms. Nevertheless, the equation form can be selected based on sensor application and implementation. For example, if the measured object has narrow concentration range, then a linear fit is adequate for the calibration. Moreover, for the sensor implementation in mobile and portable monitoring devices, complex calibration equation may consume much memory of the devices for processing the measured data.

The calibration curve from this experiment was only applied to incense smoke particles. The evaluated PM sensors utilize particle scattered light intensity so that particle properties, e.g., refractive index, density, shape, size, and even particle composition, would affect the sensor output. Different particle compositions affect the magnitude of scattered and absorbed light intensity of the sensor (Rai et al., 2017). For example, Wang et al. (2015) found that organic particles absorb more light than inorganic particles due to energy storage in its carbon bonds that decreases the light intensity to the detector. The particle size also has a significant impact on the sensor output. Usually, PM sensors have higher sensitivity to larger particles because they scatter more light. This also applies to the geometrical standard deviation of the particle size distribution. Higher standard deviation (wide size distribution) was found to increase the sensor output because it presents more large particles (Liu et al., 2017). In addition, the sensor output can be affected not only by the particle properties, but also by the sensor design. Sensors that use a laser diode as the light source have better sensitivity to smaller particle (Wang et al., 2015; Liu et al., 2017). The sensor aerosol pathway also contributed to the size detection performance of the sensor. Large particles may impact and be deposited on the pathway when gentle inlet airflow is applied. Because of many factors that can attribute to the PM sensor output, calibration factors for other particle sources were needed to guarantee a high accuracy measurement.

\section{Precision of PM Sensors}

The precision of PM sensors was characterized by the standard deviation $(\sigma)$ and coefficient of variation $(\mathrm{CV})$.
Environmental Protection Agency (EPA) issued an acceptable CV value below $10 \%$ for PM measurement devices (EPA, 2016). Compared to the HPMA reference monitor, the standard deviation and coefficient of variation of the evaluated PM sensors are depicted in Fig. 13. Among the evaluated PM sensors, the SDS0 sensor had relatively constant $\sigma$ and $\mathrm{CV}$ over PM concentration value with the lowest $\sigma_{\text {average }}$ and $\mathrm{CV}_{\text {average }}$ of $10.016 \mu \mathrm{g} \mathrm{m}^{-3}$ and $4.048 \%$, respectively. The $\mathrm{ZH} 03$ sensor had higher $\sigma_{\text {average }}$ and $\mathrm{CV}_{\text {average }}$ of $22.193 \mu \mathrm{g} \mathrm{m}^{-3}$ and $5.92 \%$, respectively. Considering the CVs, both of the sensors had the relatively acceptable precision to be used as PM monitoring devices.

The $\sigma$ and CV of the GP2Y sensor were calculated after the conversion of the sensor analog output to particle mass concentration using the least square fit in Table 3. Compared to the SDS0 and ZH03 sensors, the GP2Y sensor had significantly higher $\sigma_{\text {average }}$ and $\mathrm{CV}_{\text {average }}$ of $24.30 \mu \mathrm{g} \mathrm{m}^{-3}$ and $14.51 \%$, respectively. The CV of the GP2Y sensor also increased at lower PM concentration indicating that the sensor had less precision for measurement at low PM concentration. At the PM concentration range of 400$700 \mu \mathrm{g} \mathrm{m}^{-3}$, the GP2Y sensor had smaller CV of $5.72 \%$. The dispersed data of the GP2Y sensor (see Figs. 11(e) and 11(f)) resulted in high $\sigma$ and $\mathrm{CV}$. The diffusive particle transport of the GP2Y sensor might increase the probability of particles to be trapped inside the detection area, which led to sensor measurement error (Wang et al., 2015). The diffusive transport also makes the sensor insensitive to the changes in PM concentration. The GP2Y sensor performance can be improved by applying a special algorithm installed in the processing unit to eliminate sensor fluctuation ( $\mathrm{Li}$ et al., 2018). Furthermore, Li et al. (2018) have successfully improved the signal to noise ratio of the GP2Y sensor by applying digital filter algorithms (sliding window and low pass filter).

\section{CONCLUSIONS}

This paper has discussed the characterization of an aerosol chamber for PM sensor evaluation. Some investigations on the PM concentration uniformity, PM concentration loss,

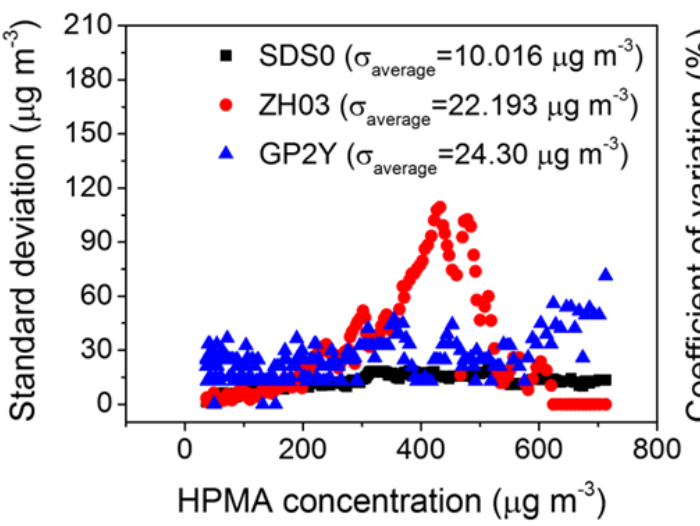

(a)

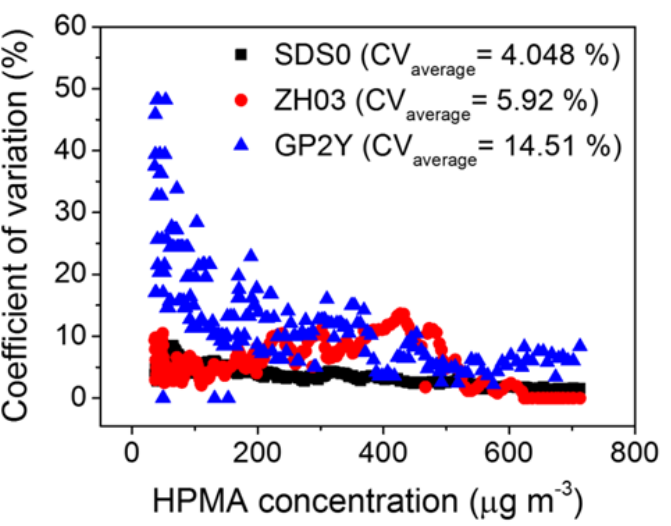

(b)

Fig. 13. (a) Standard deviation and (b) coefficient of variation of the evaluated PM sensors compared to the HPMA reference monitor. 
and concentration decay rate at different chamber volumes and output flow rates were carried out. As a result, an empirical equation was obtained to describe the PM concentration decay inside the chamber. The equation was used to predict the measurement time and the number of data points prior to conducting the experiment. The chamber was then utilized to evaluate three PM sensors, viz., the Sharp GP2Y1010AU0F, Winsen ZH03A, and Novafitness SDS011 models. A condensation particle counter (TSI, 3025A) and particle sensor (Honeywell, HPMA115S0-XXX) were employed as reference monitors for determining the linearity, calibration curve, and precision of the evaluated PM sensors. The evaluated sensors showed good linearity towards the HPMA reference monitor, with $\mathrm{R}^{2}$ values above 0.956 and the highest $\mathrm{R}^{2}$ being 0.999 for the Novafitness SDS011. The least square and RMA correlation of the evaluated PM sensors with the reference monitors depicted the best linearity achieved at a low PM measurement range $\left(0-400 \mu \mathrm{g} \mathrm{m}^{-3}\right)$. The Winsen ZH03A sensor and the Novafitness SDS011 sensor had coefficients of variation below $10 \%$, which indicates that the sensors have an acceptable precision based on the EPA standard. The laboratory evaluation results have demonstrated that the Novafitness SDS011 sensor was superior to the Sharp GP2Y1010AU0F and Winsen ZH03A sensors, implying that this sensor is suitable for implementation in a widely distributed PM monitoring system.

\section{ACKNOWLEDGMENTS}

This work was financially supported by the University's Excellence Research (PUPT) Grant from the Ministry of Research, Technology, and Higher Education, the Republic of Indonesia, in the fiscal year 2017-2018. D. A. H. gratefully acknowledges the Ministry of Research, Technology, and Higher Education Indonesia for the provision of master leading to doctoral scholarship (PMDSU).

\section{REFERENCES}

Abril, G.A., Diez, S.C., Pignata, M.L. and Britch, J. (2016). Particulate matter concentrations originating from industrial and urban sources: Validation of atmospheric dispersion modeling results. Atmos. Pollut. Res. 7: 180-189.

Betha, R., Pradani, M., Lestari, P., Joshi, U.M., Reid, J.S. and Balasubramanian, R. (2013). Chemical speciation of trace metals emitted from Indonesian peat fires for health risk assessment. Atmos. Res. 122: 571-578.

Bowman, F.M., Odum, J.R., Seinfeld, J.H. and Pandis, S.N. (1997). Mathematical model for gas-particle partitioning of secondary organic aerosols. Atmos. Environ. 31: 3921-3931.

Chen, F., Zhou, H., Gao, J. and Hopke, P.K. (2017). A chamber study of secondary organic aerosol (SOA) formed by ozonolysis of d-limonene in the presence of NO. Aerosol Air Qual. Res. 17: 59-68.

Cheng, Z., Jiang, J., Fajardo, O., Wang, S. and Hao, J. (2013). Characteristics and health impacts of particulate matter pollution in China (2001-2011). Atmos. Environ. 65: 186-194.

Chien, C.H., Theodore, A., Wu, C.Y., Hsu, Y.M. and Birky, B. (2016). Upon correlating diameters measured by optical particle counters and aerodynamic particle sizers. J. Aerosol Sci. 101: 77-85.

Cocker, D.R., Flagan, R.C. and Seinfeld, J.H. (2001). State-of-the-art chamber facility for studying atmospheric aerosol chemistry. Environ. Sci. Technol. 35: 2594-2601.

Dacunto, P.J., Klepeis, N.E., Cheng, K.C., AcevedoBolton, V., Jiang, R.-T., Repace, J.L., Ott, W.R. and Hildemann, L.M. (2015). Determining $\mathrm{PM}_{2.5}$ calibration curves for a low-cost particle monitor: common indoor residential aerosols. Environ. Sci. Processes Impacts 17: 1959-1966.

EPA (2016). 40 CFR Parts 58-Ambient Air Quality Surveillance (Subchapter C). Washington, DC.

Fujii, Y., Kawamoto, H., Tohno, S., Oda, M., Iriana, W. and Lestari, P. (2015). Characteristics of carbonaceous aerosols emitted from peatland fire in Riau, Sumatra, Indonesia (2): Identification of organic compounds. Atmos. Environ. 110: 1-7.

Gu, F., Yang, J., Wang, C., Bian, B. and dan He, A. (2010). Mass concentration calculation with the pulse height distribution of aerosols and system calibration. Optik 121: 1-10.

Heim, M., Mullins, B.J., Umhauer, H. and dan Kasper, G. (2008). Performance evaluation of three optical particle counters with an efficient "multimodal" calibration method. J. Aerosol Sci. 39: 1019-1031.

Hermann, M., Wehner, B., Bischof, O., Han, H.S., Krinke, T., Liu, W., Zerrath, A. and Wiedensohler, A. (2007). Particle counting efficiencies of new TSI condensation particle counters. J. Aerosol Sci. 38: 674-682.

IPCC (2013). Climate Change 2013: The physical science basis. Contribution of working group I to the fifth assessment report of the intergovernmental panel on climate change. Stocker, T.F., Qin, D., Plattner, G.K., Tignor, M., Allen, S.K., Boschung, J., Nauels, A., Xia, Y., Bex, V. and Midgley, P.M. (Eds.), Cambridge University Press, Cambridge, United Kingdom and New York, NY, USA, pp. 465-570.

Jovašević-Stojanović, M., Bartonova, A., Topalović, D., Lazović, I., Pokrić, B. and Ristovski, Z. (2015). On the use of small and cheaper sensors and devices for indicative citizen-based monitoring of respirable particulate matter. Environ. Pollut. 206: 696-704.

Karlsson, H.L., Gustafsson, J., Cronholm, P. and Möller, L. (2009). Size-dependent toxicity of metal oxide particlesA comparison between nano- and micrometer size. Toxicol. Lett. 188: 112-118.

Khunsongkiet, P. and Boonchieng, E. (2017). Converting air quality monitoring low cost sensor data to digital value via mobile interface. BMEiCON $2016-9^{\text {th }}$ Biomedical Engineering International Conference. pp. 198-202.

Lestari, P. and Savitri (2003). Atmospheric particulate concentration measured in an urban area Bandung. Pure Appl. Geophys. 160: 107-116.

Li, J. and Biswas, P. (2017). Optical characterization 
studies of a low-cost particle sensor. Aerosol Air Qual. Res. 17: 1691-1704.

Li, J., Li, H., Ma, Y., Wang, Y., Abokifa, A.A., Lu, C. and Biswas, P. (2018). Spatiotemporal distribution of indoor particulate matter concentration with a low-cost sensor network. Build. Environ. 127:138-147.

Liu, C., Hsu, P.C., Lee, H.W., Ye, M., Zheng, G., Liu, N., Li, W. and Cui, Y. (2015). Transparent air filter for high-efficiency $\mathrm{PM}_{2.5}$ capture. Nat. Commun. 6: 6205.

Liu, D., Zhang, Q., Jiang, J. and Chen, D.R. (2017). Performance calibration of low-cost and portable particular matter (PM) sensors. J. Aerosol Sci. 112: 110.

Manikonda, A., Zíková, N., Hopke, P.K. and Ferro, A.R. (2016). Laboratory assessment of low-cost PM monitors. J. Aerosol Sci. 102: 29-40.

Patashnick, H. and Rupprecht, E.G. (1991). Continuous $\mathrm{PM}_{10}$ measurements using the tapered element oscillating microbalance. J. Air Waste Manage. Assoc. 41: 10791083.

Rai, A.C., Kumar, P., Pilla, F., Skouloudis, A.N., Di Sabatino, S., Ratti, C., Yasar, A. and Rickerby, D. (2017). End-user perspective of low-cost sensors for outdoor air pollution monitoring. Sci. Total Environ. 607-608: 691705.

Ramachandran, G., Adgate, J.L., Pratt, G.C. and Sexton, K. (2003). Characterizing indoor and outdoor 15 minute average $\mathrm{PM}_{2.5}$ concentrations in urban neighborhoods. Aerosol Sci. Technol. 37: 33-45.

Rim, D., Green, M., Wallace, L., Persily, A. and Choi, J.I. (2012). Evolution of ultrafine particle size distributions following indoor episodic releases: Relative importance of coagulation, deposition and ventilation. Aerosol Sci. Technol. 46: 494-503.

Sahani, M., Zainon, N.A., Wan Mahiyuddin, W.R., Latif, M.T., Hod, R., Khan, M.F., Tahir, N.M. and Chan, C.C. (2014). A case-crossover analysis of forest fire haze events and mortality in Malaysia. Atmos. Environ. 96: 257-265.

Shi, Y., Matsunaga, T., Yamaguchi, Y., Li, Z., Gu, X. and Chen, X. (2018). Long-term trends and spatial patterns of satellite-retrieved $\mathrm{PM}_{2.5}$ concentrations in South and Southeast Asia from 1999 to 2014. Sci. Total Environ. 615: 177-186.

Sousan, S., Koehler, K., Thomas, G., Park, J.H., Hillman, M., Halterman, A. and Peters, T.M. (2016). Intercomparison of low-cost sensors for measuring the mass concentration of occupational aerosols. Aerosol Sci.
Technol. 50: 462-473.

Sousan, S., Koehler, K., Hallett, L. and Peters, T.M. (2017). Evaluation of consumer monitors to measure particulate matter. J. Aerosol Sci. 107: 123-133.

Soysal, U., Géhin, E., Algré, E., Berthelot, B., Da, G. and Robine, E. (2017). Aerosol mass concentration measurements: Recent advancements of real-time nano/micro systems. J. Aerosol Sci. 114: 42-54.

Wang, X., Chancellor, G., Evenstad, J., Farnsworth, J.E., Hase, A., Olson, G.M., Sreenath, A. and Agarwal, J.K. (2009). A novel optical instrument for estimating size segregated aerosol mass concentration in real time. Aerosol Sci. Technol. 43: 939-950.

Wang, X., Liu, T., Bernard, F., Ding, X., Wen, S., Zhang, Y., Zhang, Z., He, Q., Lü, S., Chen, J., Saunders, S. and $\mathrm{Yu}$, J. (2014). Design and characterization of a smog chamber for studying gas-phase chemical mechanisms and aerosol formation. Atmos. Meas. Tech. 7: 301-313.

Wang, Y., Li, J., Jing, H., Zhang, Q., Jiang, J. and Biswas, P. (2015). Laboratory evaluation and calibration of three low-cost particle sensors for particulate matter measurement. Aerosol Sci. Technol. 49: 1063-1077.

WHO (2005). WHO Air quality guidelines for particulate matter, ozone, nitrogen dioxide and sulfur dioxide: Global update 2005, Genebra, pp. 1-21.

Yan, F., Winijkul, E., Jung, S., Bond, T.C. and Streets, D.G. (2011). Global emission projections of particulate matter (PM): I. Exhaust emissions from on-road vehicles. Atmos. Environ. 45: 4830-4844.

Yang, X., Yang, L. and Zhang, J. (2017). A WiFi-enabled indoor air quality monitoring and control system: The design and control experiments. IEEE International Conference on Control and Automation, ICCA, pp. 927932.

Zhang, R., Liu, C., Hsu, P.C., Zhang, C., Liu, N., Zhang, J., Lee, H.R., Lu, Y., Qiu, Y., Chu, S. and Cui, Y. (2016). Nanofiber air filters with high-temperature stability for efficient $\mathrm{PM}_{2.5}$ removal from the pollution sources. Nano Lett. 16: 3642-3649.

Zhao, Y., Wang, F. and Zhao, J. (2015). Size-resolved ultrafine particle deposition and Brownian coagulation from gasoline vehicle exhaust in an environmental test chamber. Environ. Sci. Technol. 49: 12153-12160.

Received for review, December 31, 2017 Revised, May 15, 2018 Accepted, June 7, 2018 